\title{
A Research of Islanding Detection Method for Distributed Generation: Mechanism, Merits and Demerits
}

\author{
Nuraishahtul Amirah Fadzil, Mohd Hendra Hairi, Farhan Hanaffi, Muhammad Nizam \\ Kamarudin, Ahmad Sadhiqin Isira, Mohamed Fauzi Packeer Mohamed
}

\begin{abstract}
Renewable energy is substantially applied at the distribution grid in order to fulfill the electricity demand as well as addressing global heating issue caused by conventional energy source. However, application of the distributed energy source raises new concern in regards of unintentional islanding activity in which prompts grid protection issues hence, endangering utility worker's safety. These several decades feature thousands of invention and innovation of anti-islanding method developed by researchers to satisfy the demand of grid protection. Therefore, this paper conducts an overview on several islanding detection schemes with concentration on the mechanism of the method, the merits as well as the demerits of the scheme. It is concluded that there is no ideal method developed as yet, but some of these methods or integration of them are able to be applied practically to specific distributed source and grid structure.
\end{abstract}

Keywords: Distributed generation, grid protection, islanding detection method, review.

\section{INTRODUCTION}

Conventional electrical energy grid systems portray unidirectional flow of energy which begins from the energy source to the distribution grid, through the transmission grid [1]. These conventional power plants are one of the main contributors to the polluted environment hence as well as the global heating issue. Having these problems at hand, people starts to hugely utilize renewable energy like solar and hydro energy as an electricity generating source. These types of energy generation usually occur or applied at the distribution area of the electrical energy grid which is then, well-known as distributed generation, DG [2]. Thus, the former conventional electrical energy grid systems are transformed. While the implementation of DGs has negligible effects to the environment, nonetheless DGs affect the existing control and protection systems of

Revised Manuscript Received on September 14, 2019.

Nuraishahtul Amirah Mohd Fadzil*, Faculty of Electrical Engineering, Technical University of Malaysia Malacca, Malacca, Malaysia. (Email: nuraishahtulamirah@gmail.com)

Mohd Hendra Hairi, Faculty of Electrical Engineering, Technical University of Malaysia Malacca, Malacca, Malaysia. (Email: hendra@utem.edu.my)

Farhan Hanaffi, Faculty of Electrical Engineering, Technical University of Malaysia Malacca, Malacca, Malaysia. (Email: farhan@utem.edu.my)

Muhammad Nizam Kamarudin, Faculty of Electrical Engineering, Technical University of Malaysia Malacca, Malacca, Malaysia. (Email: nizamkamarudin@utem.edu.my)

Ahmad Sadhiqin Mohd Isira, Faculty of Electronics and Computer Engineering, Technical University of Malaysia Malacca, Malacca, Malaysia. (Email: sadhiqin@utem.edu.my)

Mohamed Fauzi Packeer Mohamed, School of Electrical and Electronics Engineering, Science University of Malaysia, Penang, Malaysia. (Email: fauzi.packeer@usm.my. ) electrical energy grid. One of the greatest concerns is the occurrence of the unintentional islanding phenomenon [3].

Islanding in regards to IEEE standard 1547, is a situation in which a proportion of the electrical energy grid is disconnected or electrically isolated from the main grid but remain in operation with one or more DG units supplying electricity to the load in the island [4]. Islanding can either be intentional or unintentional. Intentional islanding is a purposeful isolation of a proportion of the grid during fault or disturbance in which can be designed to assist continuity supplying electrical energy to the load demand [5]. In contrast, unintentional islanding is an uncontrollable operation which brings serious danger to the utility workers as well as the DG units in the island [4]. The concern is mainly in regards to the fluctuation and variation of the voltage and frequency. Stability interference of the systems might cause complication for proper automatic grid reconnection and restoration [6].

Therefore, existing international standards prohibit the operation of unintentional islanding hence, encouraging researchers to develop efficient islanding detection method, IDM [3]. These standards demand stringent requirements mainly in regards to the detection period, frequency and voltage, and utilized as the benchmark in order to develop new IDM. For an instance, the IEEE 1547 standard demands that the islanding operation should be detected and halted within $2 \mathrm{~s}$ [6]. A digestion of the main international standards is as shown in Table I where $V_{0}$ stands for nominal voltage and $f_{0}$ stands for nominal frequency [7].

Several IDMs were developed and proposed over the last decade in which each method owns distinctive advantages and disadvantages [8]. This paper presents a review of some of these IDMs concentrating on mechanism of the method, merits and demerits. The paper is organized as follows: in Section II, classification of IDMs and the methods are discussed in Section III for local method, Section IV for communication-based method, Section $\mathrm{V}$ for signals processing (SP) based method, and Section VI for intelligent-based method. Hence, Section VII provides conclusion of the review 


\section{A RESEARCH OF ISLANDING DETECTION METHOD FOR DISTRIBUTED GENERATION: MECHANISM, MERITS AND DEMERITS}

Table- I: Main International Standards for IDM

\begin{tabular}{|c|c|c|c|c|c|c|}
\hline $\begin{array}{l}\text { Stand } \\
\text { ards }\end{array}$ & $\begin{array}{l}\text { Qua } \\
\text { lity } \\
\text { Fact } \\
\text { or, } \\
Q_{f}\end{array}$ & $\begin{array}{l}\text { Detec } \\
\text { tion } \\
\text { Perio } \\
\text { d, } \quad t \\
\text { (s) }\end{array}$ & $\begin{array}{l}\text { Mini } \\
\text { mum } \\
\text { Volta } \\
\text { ge, } \\
V_{\text {min }} \\
(\% \text { of } \\
\left.V_{0}\right)\end{array}$ & $\begin{array}{l}\text { Maxi } \\
\text { mum } \\
\text { Volta } \\
\text { ge, } \\
V_{\text {max }} \\
(\% \text { of } \\
\left.V_{0}\right)\end{array}$ & $\begin{array}{l}\text { Mini } \\
\text { mum } \\
\text { Frequ } \\
\text { ency, } \\
\boldsymbol{f}_{\min } \\
(\mathbf{H z})\end{array}$ & $\begin{array}{l}\text { Maxi } \\
\text { mum } \\
\text { Frequ } \\
\text { ency, } \\
f_{\text {max }} \\
(\text { Hz) }\end{array}$ \\
\hline $\begin{array}{l}\text { IEC } \\
62116 \\
\end{array}$ & 1 & $<2$ & 85 & 115 & $f_{0}-1.5$ & $\begin{array}{l}f_{0}+ \\
1.5\end{array}$ \\
\hline $\begin{array}{l}\text { IEEE } \\
929- \\
2000 \\
\end{array}$ & 2.5 & $<2$ & 88 & 110 & 59.3 & 60.5 \\
\hline $\begin{array}{l}\text { IEEE } \\
1547- \\
2003 \\
\end{array}$ & 1 & $<2$ & 88 & 110 & 59.3 & 60.5 \\
\hline $\begin{array}{l}\text { Korea } \\
\mathrm{n}\end{array}$ & 1 & $<0.5$ & 88 & 110 & 59.3 & 60.5 \\
\hline $\begin{array}{l}\text { VDE } \\
0126- \\
1-1 \\
\end{array}$ & 2 & $<0.2$ & 80 & 115 & 47.5 & 50.2 \\
\hline
\end{tabular}

\section{ISLANDING DETECTION METHODS (IDM) \& METHODOLOGY}

IDMs can be broadly classified as classical method and modern method. Classical method includes local method and communication-based or remote method, while modern method includes SP-based, method and artificial intelligence (AI) method [6]. Fig. 1 shows the classification of the IDMs based on the principle of mechanism. The upcoming sections review some of these methods concentrating on the mechanism, merits, and demerits.

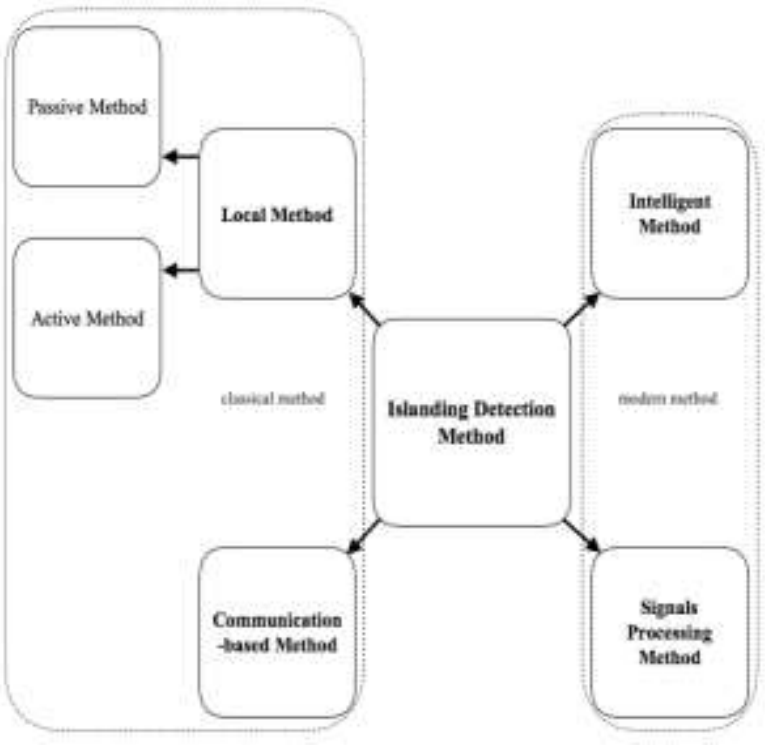

Fig. 1. Classification of IDMs

\section{CLASSICAL METHOD}

\subsection{Local Method}

Local method is based on monitoring and evaluation of the variations of some variables at the DG terminal in order to detect islanding activity [8]. Passive and active methods are the proportions of the local scheme and the integration of these methods is called hybrid method. These methods will be elaborated in the upcoming subsections.

\subsubsection{Passive Method}

Parameters at the point of common coupling (PCC) or the DG terminal are monitored and evaluated in this method in order to detect islanding [1], in which will vary substantially when the DG is disconnected with the main grid. The islanding protection relay (anti-islanding scheme) detects the variations and ceases the DG activity when the variations surpassed the predefined threshold [10]. The primary steps of the method are as shown in Fig. 2. There are several disadvantages of this method including big NDZ and threshold selection issues. NDZ is defined as the grid operating area where the islanding occurrence is unable to be detected in a specified period [11]. However, the method is preferred by the utility provider in view of the coherent of application as well as the economical attribute [12]. Several notable schemes in related to this method including Over/Under Voltage (OUV) and Over/Under Frequency, Rate of Change of Power (ROCOP), Rate of Change of Frequency (ROCOF), Voltage Phase Jump Detection (PJD), Voltage Unbalance (VU), Total Harmonic Distortion (THD), and Change of Impedance schemes in which are described in succeeding subsections.

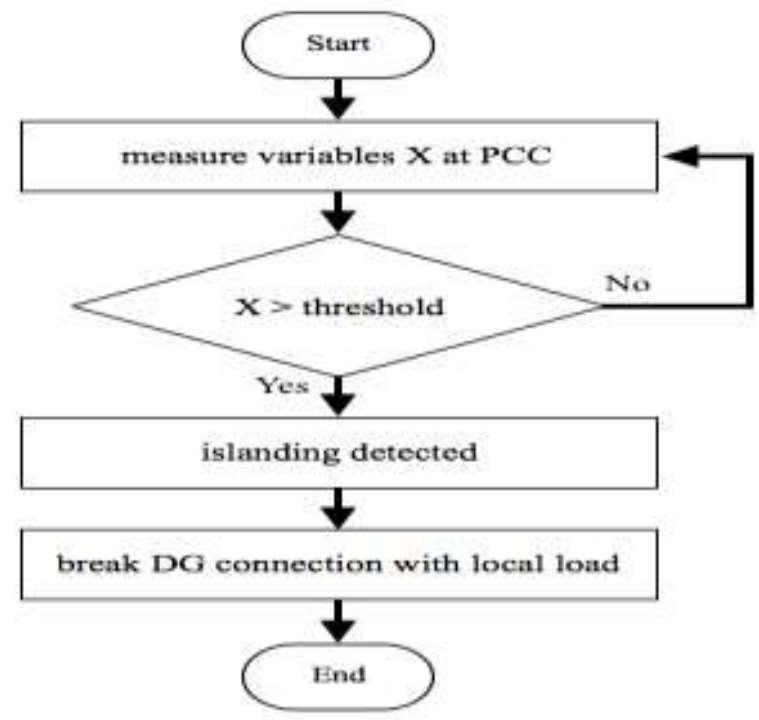

Fig. 2. Flow chart of passive IDM

\section{A. Over/Under Voltage (OUV) and Over/Under} Frequency $(O U F)$

These methods are one of the oldest and easiest methods adapted to the distribution grid protection [1], [8]. Voltage and frequency variations at the PCC or DG terminals are monitored in these schemes, and then compared to the threshold settings. Islanding phenomenon is predicted to happen when the threshold setting is breached, hence, triggering the disconnection of the DG [14]. The NDZ of these methods can be illustrated by the upcoming Fig. 3 in which the grey area constitutes the NDZ [15]. $\Delta P$ stands for variation of active power whereas $\Delta Q$ stands for variation of reactive power. The defect of the method is mainly owing to the big NDZ, though the application is uncomplicated and economical 


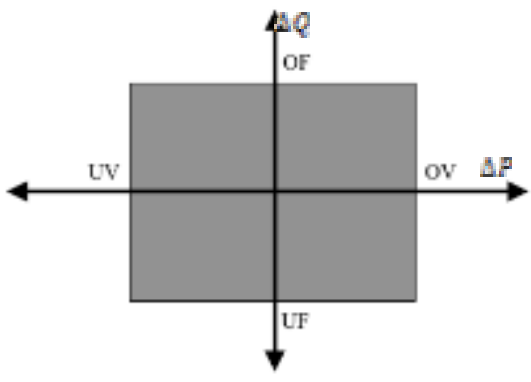

Fig. 3. NDZ area for OUV/F IDM

\section{B. Rate of Change of Power (ROCOP)}

Power variations of DG output over a specified period $(d P / d t)$ are being monitored in this method in order to detect islanding situation in which as expressed in (1)

$$
\frac{d P}{d t}=\sum_{n=-t x}^{0}\left(P_{D G}\right)_{n} \#(1)
$$

In an incident of islanding, the ROCOP surpassed the selected threshold hence; the breaker is activated to cease the DG activity [16]. There is Rate of Change of Active Power (ROCOAP) as well as Rate of Change of Reactive Power (ROCORP) schemes. The instantaneous active power $(P)$ and reactive power $(Q)$ at the PCC are evaluated in (2) and (3) accordingly.

$P_{D G}=v_{a} i_{a} \cos \left(\theta_{a}\right)+v_{b} i_{b} \cos \left(\theta_{b}\right)+v_{c} i_{c} \cos \left(\theta_{c}\right) \#(2)$

$P_{D G}=v_{a} i_{a} \cos \left(\theta_{a}\right)+v_{b} i_{b} \cos \left(\theta_{b}\right)+v_{c} i_{c} \cos \left(\theta_{c}\right) \#(3)$

where the voltage $v_{a}, v_{b}$ and $v_{c}$ as well as current $i_{a}, i_{b}$ and $i_{c}$ are taken at the DG output. ROCOAP and ROCORP can be attained by differentiating (2) and (3) as demonstrated in (1) [17]. These methods are more efficient in detecting islanding phenomenon compared to the OUV/F method appropriate to the rapid islanding detection and smaller NDZ [10]. Nowadays, a lot of researchers extend attentions to the utilization of the ROCORP method entitled to the easiness and efficiency in which can be further comprehend in [18], [19]. Nonetheless, the NDZ area for ROCOP is still big if the method is utilized without

\section{Rate of Change of Frequency (ROCOF)}

ROCOF scheme is based on monitor of variations of the instantaneous output frequency of the voltage at DG terminals [12], [20]. Islanding phenomenon causes fluctuations of the frequency in which the greater the grid disturbance, the greater the frequency fluctuations [1]. These fluctuations are known as ROCOF and can be demonstrated in (4) hereinafter

$$
\mathbf{\square}\left(\frac{d f}{d t}=-\frac{P_{L}-P_{G}}{2 H \cdot S_{G N}} f_{r} \#(4)\right)
$$

where $P_{L}$ is the total DG load, $P_{G}$ is the total DG active power output, $H$ is the inertia constant, $S_{G N}$ is the DG rated capacity, and $f_{r}$ is the rated frequency. Equation (4) assumes that the DG is operating at rated frequency [21]. If the calculated ROCOF $(d f / d t)$ surpassed the assigned threshold, then an islanding situation is presumed hence, the DG activity will be terminated [16]. Identical to ROCOP, this method harbors rapid islanding detection and smaller NDZ compared to OUV/F method, thus attracting numerous integration with other methods.

researches on the ROCOF utilization and enhancement with method integration [21]-[23].

\section{Voltage Phase Jump Detection (PJD)}

The PJD method utilized monitoring of the phase difference of output voltage and current at DG terminals in order to detect islanding phenomenon. Usually, the voltage and current are in synchronization through the phase locked loop (PLL) control structure [16]. The DG output current remains unchanged when there is an islanding situation; meanwhile the voltage deviated, out of phase, hence creating the phase difference as shown in Fig. 4 [15]. PJD scheme will evaluate the phase difference in which is compared to the specified threshold for islanding identification [24]

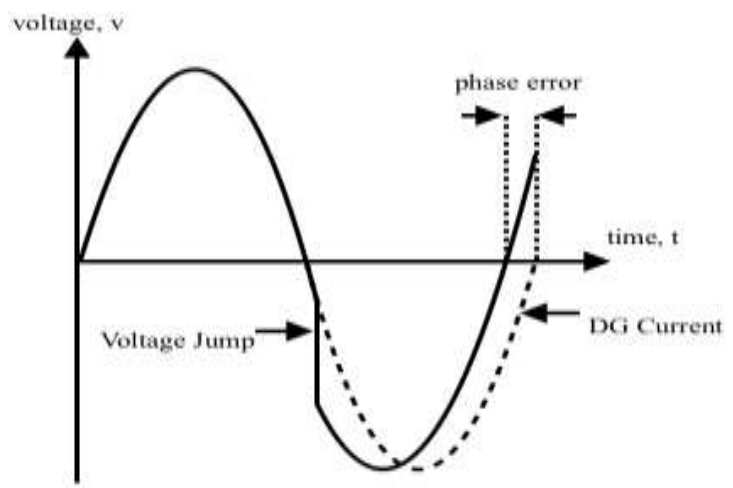

Fig. 4. Voltage jumping and phase error during islanding

The merits of this method are the ease of implementation and the ability to be utilized in multi-inverter structure [15]. However, PJD method could be affected by reactive elements of the circuit which is commonly found in industrial applications in addition to possessing a big NDZ. The NDZ of PJD is derived by applying in (5) as shown.

$$
\tan ^{-1}\left(\frac{\frac{\Delta Q}{P}}{1+\left(\frac{\Delta P}{P}\right)}\right) \leq \vartheta_{\text {threshold }} \#(5)
$$

where $\vartheta_{\text {threshold }}$ is the PJD threshold [10]. Though, the NDZ of PJD method is still smaller than the standard OUV/F method [8].

\section{E. Voltage Unbalance (VU)}

Unbalance in voltage (VU) arises when changes occur in the DG loading even when the change is nominal. Hence, islanding detection is practicable by monitoring the three phase output voltages of the DG [8]. The VU at time $t$ is defined as in (6).

$$
V U_{t}=\frac{N S_{t}}{P S_{t}} \times 100 \#(6)
$$

where $N S_{t}$ is amplitude of the negative sequence of the voltage, while $P S_{t}$ is amplitude of the positive sequence of the voltage at time $t$ [25]. VU method is efficient and capable for load fluctuations applications. However, the sequence extraction procedure is affected by harmonics, hence increases complication in threshold selection [26]. 


\section{A RESEARCH OF ISLANDING DETECTION METHOD FOR DISTRIBUTED GENERATION: MECHANISM, MERITS AND DEMERITS}

\section{F. Total Harmonic Distortion (THD)}

A common grid, usually contains low voltage harmonics in which the standard of harmonic distortion is less than $5 \%$, $(\mathrm{THD}<5 \%)$ [24]. However, the THD is negligible as the voltage of the grid and the PCC are match. When an islanding occurs, the grid is disconnected with the DG; hence the DG will be directly connected to the local load. The situation increases the harmonic levels; hence islanding phenomenon is detected when the THD surpassed the specified threshold [16]. The merits of THD scheme is the ability to adapt in multi-inverter structure. Though, the method is afflicted by mistaken the switching of non-linear loading as islanding phenomenon [24].

\section{G. Change of Impedance}

The main principle of this method is the same as the THD method. Usually, the impedance content in the DG is small. The impedance in the islanded grid is abruptly increases when the DG is disconnected from the grid [16]. The frequency dependent change of the impedance will be utilized in the anti-islanding strategy. The islanding phenomenon is detected when specified impedance change is detected at specified harmonics [27]. Once the predefined threshold is violated, the DG activity will be ceased. Change of impedance can be utilized and enhanced by deploying active scheme in which specified harmonics is introduced at the PCC [28].

\subsubsection{Active Method}

Passive method inherits the limitation of big NDZ, hence in 1997; researchers start to invent active method to enhance anti-islanding strategy. The main principle of active method is continual injection of small perturbation at specified interval, to specified variables in the DG output [6]. These perturbation injections bring crucial change in the variables when an islanding phenomenon occurs; otherwise the perturbation is rather negligible. Active method detects, hence block the islanding activity by monitoring the variations produced by the interference [24]. The main principle of the active method is as shown in Fig. 5. Several common active methods including Impedance Measurement (IM), Sliding/Slip Mode Frequency Shift (SMFS), Frequency Bias or Active Frequency Drift (AFD), Frequency Jump (FJ), Active Frequency Drift with Positive Feedback (AFDPF), Sandia frequency Shift (SFS), and Sandia Voltage Shift (SVS) are further discussed in the upcoming subsections.

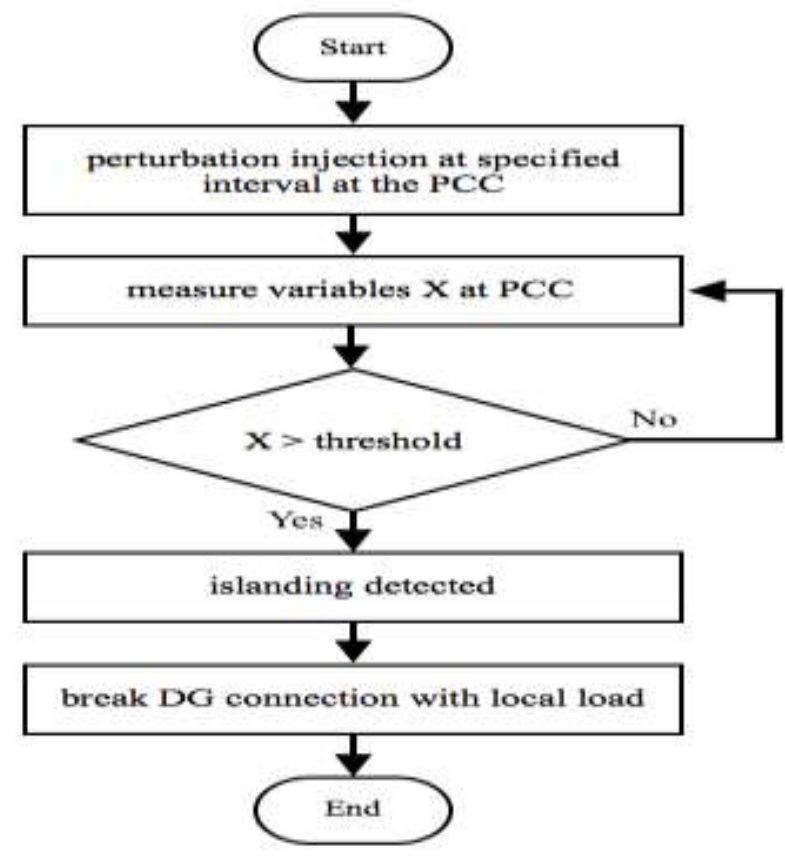

Fig. 5. Flow chart of active IDM

\section{A. Impedance Measurement (IM)}

IM method measures impedance variations at the DG output in order to detect islanding activity [30]. These impedance variations are induced by the varying DG output voltage in which in return is incited by the perturbation injection delivered at the DG output [16]. The variations are evaluated by utilizing rate of change of voltage with reference to current $(d v / d i)$ of the DG output [27]. If the $d v / d i$ overshoots the predefined threshold, then islanding phenomenon is considered to occur [6].

The benefit of this method is the small NDZ, whereas main detriment of IM is the efficiency reduction with quantity of the DG that operates non-synchronously [30]. Besides, the impedance threshold is hard to decide as an accurate grid impedance is required whilst it is highly intermittent and initially unknown [16], [25].

\section{B. Sliding/Slip Mode Frequency Shift (SMFS)}

In SMFS scheme, anti-islanding strategy is performed based on application of positive feedback to the phase angle of the DG [31]. The voltage phase at the PCC is shifted in an episode of islanding and then, changes in the frequency are monitored in order to detect islanding phenomenon [32]. SMFS method control the DG phase angle as a sinusoidal function of frequency deviation of the PCC voltage from the nominal frequency which is defined in (7) [31].

$$
\theta_{S M S}=\theta_{m} \sin \left(\frac{\pi}{2} \cdot \frac{f-f_{g}}{f_{m}}\right) \#(7)
$$

where $f$ is the DG frequency, $f_{g}$ is the nominal grid frequency, $\theta_{m}$ is the maximum phase angle, and $f_{m}$ is the maximum frequency at $\theta_{m}$ [32]. Islanding causes deviation of frequency and therefore, causes phase reaction error. The 
error accumulated to achieve steady state phase where the phase angle of both SMS and RLC load is equal as shown in Fig. 6 [33]. When the steady state phase of the frequency surpassed the predefined area, islanding is detected hence, terminating the DG activity [31].

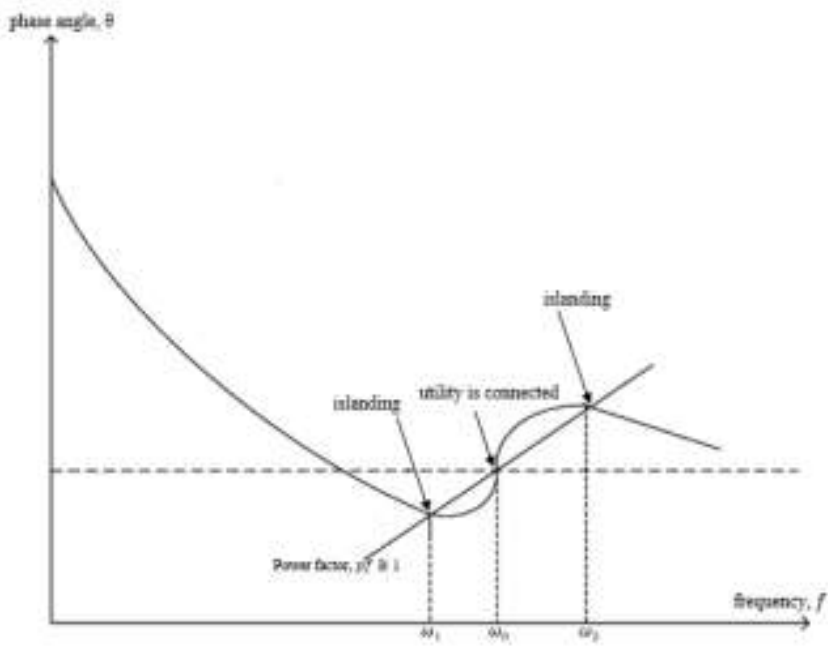

Fig. 6. Mechanism principle of SFMS IDM

SMFS is preferred for the ease of application as well as the high efficient with smaller NDZ even with multi-inverter structure [27]. However, the efficacy of SMFS is reduced with the increase of quality factor of the load [30]. Besides, the injection of the phase shift perturbation initiates noise and measurement error in addition to the matter arises in regards of the transient reaction [8], [27].

\section{Frequency Bias or Active Frequency Drift (AFD)}

Frequency bias or AFD method injects interference to the reference output of the inverter based DG in which, a period of zero conduction is introduced in every half cycle of the waveform as shown in Fig. 7 [34], [35]. The interference is defined as the chopping fraction, $c f$ (ratio of zero conduction period, $t_{z}$ to half of utility voltage period, $T_{V_{\text {utility }}}$ ) which is expressed in (8) [36].

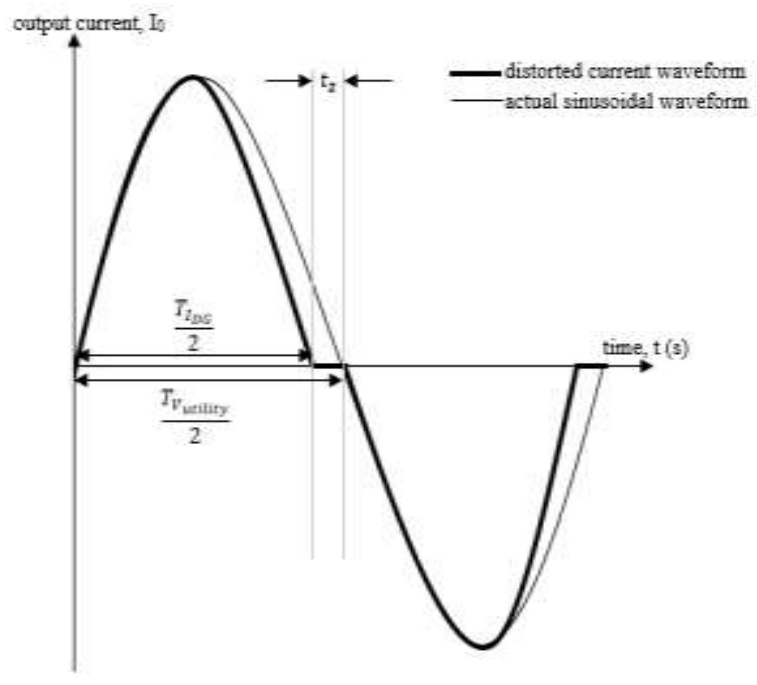

Fig. 7: AFD IDM interference injection

$$
c f=\frac{2 t_{z}}{T_{V_{u t i l i t y}}} \#(8)
$$

These interference increase phase error of the DG output during islanding phenomenon hence, leading to the frequency drift in order to eliminate the error. If the frequency drift surpassed the predefined boundary, OUF relay detects the islanding and at once ceases the DG activity [36].

The merits of AFD method are ease of application with small NDZ (depends on the chopping factor). However, the method unable to detect balanced islanding in addition to inappropriate in multi-DG application in exception of all DG uses identical AFD [26]. Therefore, AFDPF method is introduced as an enhancement of AFD which is described later.

\section{Frequency Jump (FJ)}

FJ method is an alteration of the AFD scheme in which like the AFD, FJ injects interference to the DG output. However, the interference is introduced in every several cycles, instead of to every half cycle. Otherwise stated, the frequency is dithered according to a designated order. Commonly, the interference is negligible as the utility grid influence on the voltage waveform is bigger. When the main grid is disconnected, the islanding is detected when the voltage frequency deviates and surpasses the specified border or by monitoring the frequency variation that matches the designated order [35]. Parallel connection of multiple inverters, though, affects the efficiency of the method [26].

\section{E. Active Frequency Drift with Positive Feedback} $(A F D P F)$

AFDPF is an enhancement scheme of the AFD method in order to overcome the defects in regards of multi-inverter application as well as minimize the NDZ. Positive feedback is applied in AFDPF to increase the chopping fraction hence, escalating the frequency drift and subsequently, enhancing the islanding detection efficiency. The chopping fraction of $\mathrm{k}^{\text {th }}$ cycle is as expressed in (9) [38].

$$
c f_{k}=c f_{k-1}+F\left(\Delta \omega_{k}\right) \#(9)
$$

where $c f_{k-1}$ is the chopping fraction of the $(\mathrm{k}-1)^{\text {th }}$ cycle, $F$ (function) constitutes mapping of the sampled frequency error $\Delta \omega_{k}$ in which $\omega_{k}$ is the frequency of $\mathrm{k}^{\text {th }}$ cycle and is attained in (10) [26].

$$
\Delta \omega_{k}=\omega_{k-1}-\omega_{0} \#(10)
$$

Though the method enhances AFD efficiency hence appreciably reducing NDZ, but AFDPF cause serious degradation of quality of the DG output. Besides, AFDPF scheme is unable to function properly in the application for load with high quality factor [38].

\section{F. Sandia Frequency Shift (SFS)}

SFS is entitled after Sandia National Laboratories (SNL) that developed the method [40]. SFS is almost the same as AFDPF scheme with further innovation of the AFD [36]. The chopping fraction is as represented in (11).

$$
\begin{aligned}
& c f=c f_{0}+K\left(f-f_{g}\right) \\
& =c f_{0}+K \Delta f \quad \#(11)
\end{aligned}
$$

where $c f_{0}$ is the initial chopping coefficient without frequency error or islanding activity, $\mathrm{K}$ is the acceleration constant, $f$ is voltage frequency at the PCC, and $f_{g}$ is voltage frequency of the grid [41]. In an episode of 


\section{A RESEARCH OF ISLANDING DETECTION METHOD FOR DISTRIBUTED GENERATION: MECHANISM, MERITS AND DEMERITS}

islanding, the frequency, $c f$ increases in which the increment speed is depending on the predefined variable $\mathrm{K}$. Therefore, selection strategy of variable $\mathrm{K}$ is crucial for islanding detection efficiency [40]. SFS is one of the active methods that has highest efficiency with smallest NDZ in addition to ease of implementation. However, like AFDPF, the method initiates noises and harmonics hence, reducing the DG output quality besides being affected by load with high quality factor [15], [42].

\section{G. Sandia Voltage Shift (SVS)}

As the name stated, SVS method is alike with the SFS, but rather than initiate change in voltage frequency, SVS altered the voltage amplitude. Hence in the event of islanding, the DG output voltage is drifted surpassing the predefined boundary. Therefore, OUV relay will detect and cease the islanding activity [36]. The combination of SFS and SVS is highly efficient in which the NDZ registered is almost zero. However, SVS method affects efficiency of the inverter and transient response of the grid [12]. Furthermore, active methods are known for degrading the quality of DG output [37].

\subsubsection{Hybrid Method}

Passive methods in combination with active methods create a new anti-islanding method that is called hybrid method. Hybrid methods started to be invented and promoted by researchers in 2003 [16]. Several hybrid methods include combination of Rate of Change of Reactive Power (ROCOQ) with Load Connecting Strategy [43], combination of ROCOV (where V stands for voltage) with Real Power Shift [44], Voltage Fluctuation Injection scheme that combined ROCOF or ROCOV with Correlation Factor (CF) methods [45], and combination of SMFS and ROCOF methods [4].

Other than high application capital, the main defect of these methods is longer islanding detection period which is an effect of individual activity of those methods. Passive methods are utilized as the primary islanding protection, otherwise stated, the active method is activated when the other method is unable to comprehend and interpret an islanding situation. However, these schemes substantially minimize the NDZ hence; the islanding detection efficiency is totally escalated [46]. Many of the proposed hybrid methods are still in the simulation steps, still rather far from practical application in the main utility grid [24]. The principle mechanism of hybrid method is as depicted in the chart in Fig. 8 [12].

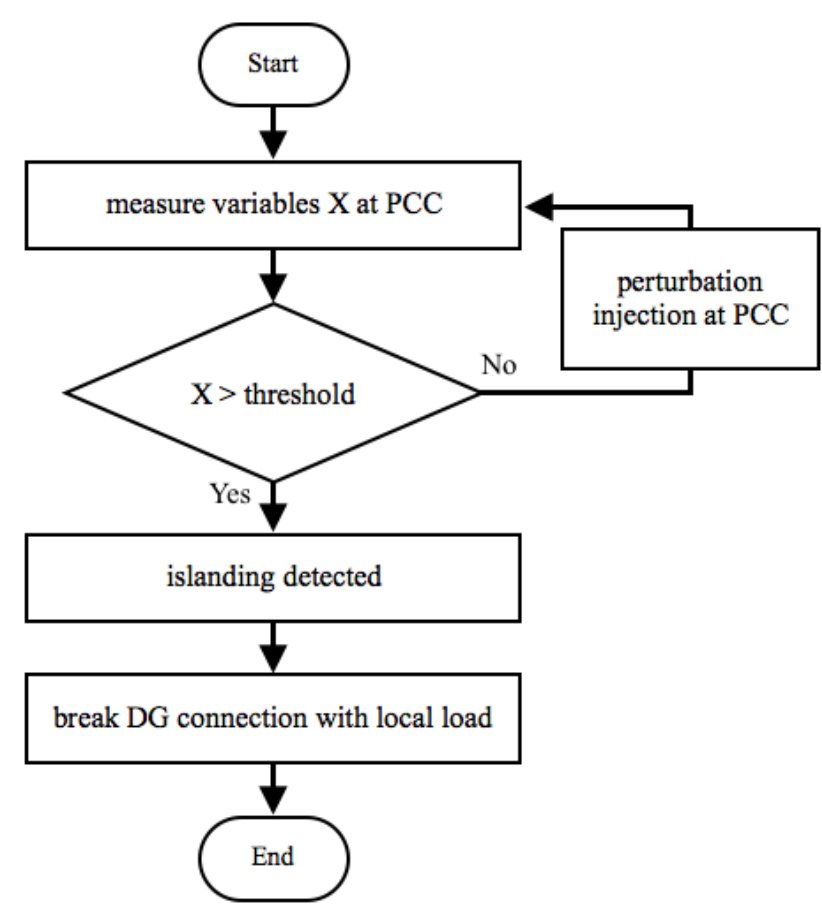

Fig. 8. Flow chart of hybrid IDM

\subsection{Communication Method}

As the name stated, remote or communication-based method operates based on communication established by the DG and the main grid [9]. Therefore, additional infrastructure is required for the communication hence the implementation of the method demand wherewithal worth a king's ransom [6]. Fig. 9 shows the schematic diagram of a common communication-based IDM. As these methods are uneconomical, the local methods are more preferred by the utility providers [9]. However, communication-based methods are highly reliable rather than the local method with no non-detection zone (NDZ) at all. Main remote IDMs include Power Line Carrier Communication (PLCC), Supervisory Control and Data Acquisition (SCADA), Impedance Insertion, Signals Produced by Disconnect (SPD), and Transfer Trip schemes.

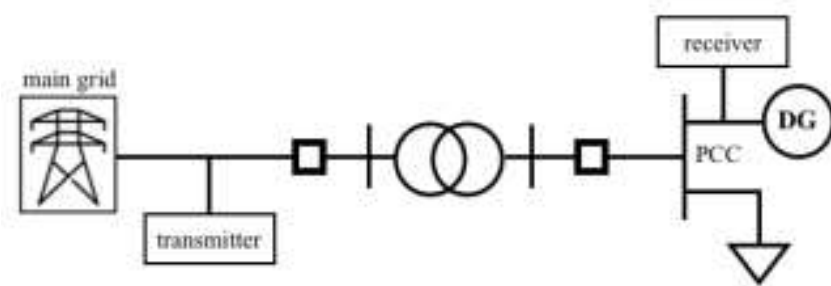

Fig. 9. Mechanism principle of communication-based IDM

\section{A. Power Line Carrier Communication (PLCC)}

PLCC scheme consists of transmitter and receiver that communicate utilizing the energy grid. The transmitter is lodged at the substation or grid area while, the receiver is located at the DG. In the anti-islanding activity, the transmitter broadcasts signal to all the receivers continuously [48], [49]. When the receiver detects zero for a 
determined period, the DG is eventually disconnected from the load hence, preventing islanding phenomenon [15]. Owing to the high capital demand, this method is worthy for substantial scale of DG installations [10].

\section{B. Supervisory Control and Data Acquisition (SCADA)}

Highly integrated communication structures and sensors are utilized in the SCADA method to detect islanding activity. The scheme involves constant monitoring of the grid connection hence, activating series of alarms to terminate the coinciding DG in an episode of islanding [12], [15]. Utilization of the SCADA method assures an in-phase activity of the grid in addition to comprehending the ability to totally eliminating NDZ [10], [49]. Besides, application of the method provides a partial or thorough DG control by the utility grid. However, the speed of islanding detection depends on the communication structure in which might drop the respond thus reducing the efficiency of the method [12]. Other than that, broad use of sensors and additional constituents increase the required expenditure and inconvenience for installation activity, making it inappropriate for small application [15], [51].

\section{Impedance Insertion}

As illustrated by the title, the method is based on insertion of low impedance to the electrical grid. When a circuit breaker $(\mathrm{CB})$ is activated, the impedance connects with the PCC hence, affecting the stability of the grid. The reaction causes voltage variation as well as phase (frequency) change in the distribution grid. The anti-islanding means initiated as the relay detects the frequency alteration. Specific delay is required ahead of restoration of the additional impedance in order to properly detect the frequency variation. The method is demonstrated as highly efficient in detecting islanding activity [53]. However, there are several limitations including high investment demand and slow reaction in which the detection period could overshoot a specific standard. Therefore, the impedance should be modified in regards to the minimum phase variation in order to be detected [15].

\section{Signal Produced by Disconnect (SPD)}

The SPD method is principally the same as the PLCC scheme. However, rather than deploying the energy grid, other communication means are applied namely microwave and telephone channels or others. Eventually, blocking crisis ascribable to faulty transmitter, channel or receiver [36]. The SPD scheme avails the ability to totally control both the grid and the DG, but the expenditure required is extortionate in addition to exhibit issues in accordance to the complicated installation [12], [15].

\section{E. Transfer Trip}

Transfer trip scheme constantly monitors all CBs which are connected to a central control element in which can be illustrated in Fig. 10 [55]. When a substation is disconnected, the central algorithm identifies the area involved and transmits order to the involved DG in order to elude unintentional islanding activity.

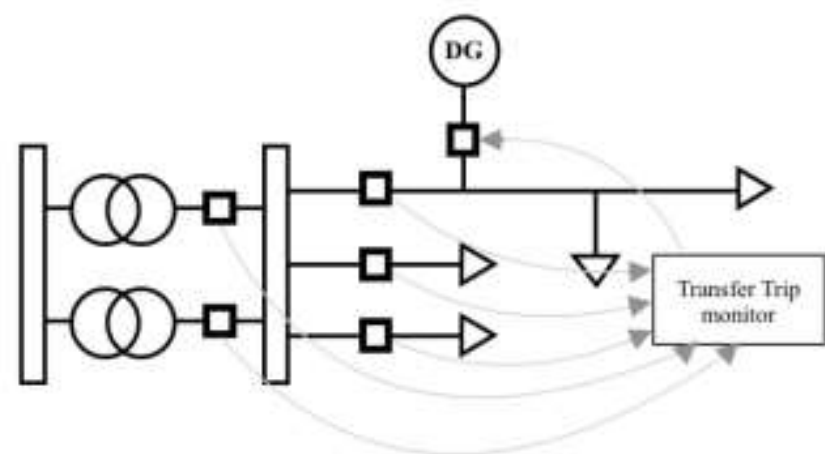

Fig. 10. An illustration of transfer trip IDM activity

The SCADA scheme commonly integrated with this method to exercise the anti-islanding strategy. This method is highly efficient with negligible NDZ as well as rapid islanding detection. However, same as the SCADA or other communication based method; the main disadvantages are high investment involved and intricate scheme which intensifies with the grid [10].

\section{MODERN METHOD \& RESULTS}

\subsection{Signal Processing (SP) Method}

Utilization of SP methods are based on the idea of extracting hidden features of signals whilst, revealing excessive information with regards to the systems. These extracted features will be evaluated, therefore helping in detection of the islanding event [6]. Principally, SP schemes are applied to enhance the islanding detection performance specifically in minimizing the detection period as well as the NDZ [10]. Nowadays, there are a lot of SP-based IDM developed by researchers [56], but only main SP schemes are discussed further here which includes Fourier Transform (FT), Wavelet Transform (WT), S-Transform (ST), TimeTime Transform (TTT), Hilbert Huang Transform (HHT), and Mathematical Morphology (MM) strategies.

\section{F. Fourier Transform (FT)}

FT is a common tool applied for the steady state analysis of the stationary signals at specified frequency in which constituted as a summation of sinusoidal signals of different frequency. Unfortunately, the FT is unable to extract the information of the time of distribution of the different frequency as well as the momentary data associated with fluctuations, making this information unavailable [56]. Therefore, the short time Fourier transform (STFT) is proposed which is modified from the FT. STFT extricates numerous small frames from the signals in which each frame is treated as stationary to be evaluated. The disadvantage is, however, the STFT is unable to interpret the non-stationary signals ascribed to the defined window's width (in regards to the method for evaluate STFT's frame) [6].

Other related means include discrete Fourier transform (DFT) and fast Fourier transform (FFT) that transform the discrete time series of a defined length into a discrete frequency series [10]. The difference between these 


\section{A RESEARCH OF ISLANDING DETECTION METHOD FOR DISTRIBUTED GENERATION: MECHANISM, MERITS AND DEMERITS}

mechanisms inheres within the quantifying efficiency in which the FFT transcends the DFT [57]. However, the FFT has problems arising from the matter of depiction of nonexisting spectral [3]. Subsequently, another method is developed namely Goertzel algorithm (GA) which outmatch DFT and FFT. In order to properly utilize GA, though, a concrete theoretical architecture is required [58], [59].

\section{G. Wavelet Transform (WT)}

In WT analysis, the signals are represented as various scales of temporary wave namely mother wavelet which produces small waves that is called wavelets [8], [56]. These wavelets have long windows at low frequency as well as short windows at high frequency enabling parallel analysis of both the time and the frequency information. Therefore, assumptions of stationary or periodicity signals (like the ST scheme) are redundant [8]. WT can be classified as continuous wavelet transform (CWT), discrete wavelet transform (DWT), and wavelet packet transform (WPT) [1].

CWT is utilized with Mallat decomposition to interpret voltage of DG and eliminate noise in the signals accordingly [60]. The method introduces numerous coefficients which cause efficiency limitation, therefore researchers concentrate on the DWT mechanism [8]. However, while CWT produces exhaustive coefficients, the DWT method mixes high frequency which prompt faulty information. Hence, WPT is introduced that utilized ROCOP output at DG terminals to detect islanding phenomenon [61]. The main disadvantages of these methods include over-sensitizing to noise signals and computational complication [62].

\section{H. Stockwell Transform (ST)}

ST method is an evolution of the WT method in eliminating the high sensitivity to noise characteristic [63]. The scheme transforms a time-based function to a twodimensional (2D) frequency-based function and operates with movable and scalable Gaussian window. Interference in excessive noise surroundings can be detected properly as the method offers multi-resolution while keeping the actual phase of the frequency constituent [8]. However, the potential of the method reduced with arise of transients, hence hyperbolic S-transform (HST) is introduced.

HST uses pseudo Gaussian hyperbolic window which comprehend changeable shape depending on the frequency. The asymmetry window contributes to high resolution in both time and frequency [6]. Despite all the assets stated, ST-based method requires bigger memory hence, longer period for the interpretation of the signals [10].

\section{Time-Time Transform (TTT)}

TTT is a feature extraction method that transforms onedimensional (1D) time-series signals to 2D time-time-series signals by assigning time-time distribution on the respected window. In this method, the high frequency data are concentered at a locality where the energy concentration is high. On the other hand, the low frequency data are dispersed at various localities [10]. TTT is tested and compared with WT, ST and HST, and as such can be concluded that the TTT scheme performs effectively in intense noise condition surpassing WT and ST methods [6], [64]. The demerit of TTT includes inadequate resolution during event initiation [3].

\section{J. Hilbert Huang Transform (HHT)}

The HHT scheme is principally developed in order for analysis of nonlinear and non-stationary signals [65]. Mainly, there are two stages involved in the HHT scheme. Stage one utilized Empirical Mode Decomposition (EMD) strategy for decomposing of the signals as Intrinsic Mode Function (IMF) which constitutes important instantaneous amplitude and frequency. These IMFs are arranged in descending order based on the frequency, that is, the earliest IMF consists of highest frequency for all episodes in the signals. Subsequently, stage two applies Hilbert transform strategy to individual IMF, hence attaining the curve of instantaneous amplitude and instantaneous frequency versus time [3]. These whole steps are known as HHT.

The main strengths of HHT strategy are the high resolution and efficiency in multi-DG application [66]. On the other hand, the HHT is inappropriate to handle data incorporated with close frequency in addition to inability to detect transition period of rapid waveform variations [16].

\section{K. Mathematical Morphology (MM)}

$\mathrm{MM}$ is a nonlinear method which is operation is based on manipulating the signals shapes [15]. The shape is manipulated by morphologically convolving the signals with structuring element (SE). SE is a variable that can be essentially changed then is utilized as a probe to extract important features from the signals [67]. There are two primary operators in MM method which are erosion and dilation in which other operators including closing and opening are procured [68]. Erosion can be illustrated as a shrinking action whereas swelling action illustrates the dilation operator [69].

The main merit of MM is high efficiency with low computational complication. On the other hand, the main issues of $\mathrm{MM}$ inhered in the nonlinearity and the inconvenience selection procedure of SE [67]. In addition, MM method is confronted with its inability of reconstruction of original signal [16].

\subsection{Intelligent Method}

Usually, intelligent scheme is applied together with SP feature extraction method which was elaborated in the former sections. In order to detect islanding activity, SP is applied to extract characteristic from the attained signals in which will be rendered as inputs for the functional intelligent. These characteristics are initially processed as a structure of feature vector which is then analyzed by the intelligent classifiers to decide occurrence of islanding. The main principle of the integration of SP feature extraction and intelligent classifiers scheme is as depicted in Fig. 11. Computational difficulty is high in the method utilization even though there is no NDZ involved [70]. Upcoming subsections will describe about this intelligent strategy which includes Artificial Neural Network (ANN), Probabilistic Neural Network (PNN), and Decision Tree (DT). 


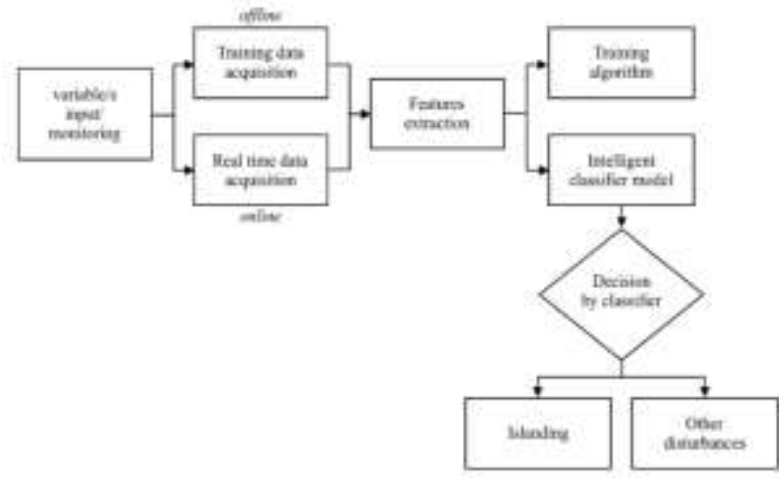

Fig. 11. Integration of SP and intelligent method for islanding detection

\section{A Artificial Neural Network (ANN)}

The main idea of ANN is the attempt to imitate the biological synapse of human to be able to study a situation as well as deciding conclusion [71]. ANN consists of neurons that build input, hidden and output as illustrates in Fig. 12. The input data is delivered to the output through hidden neurons. The error signals at the output then are redelivered to the hidden and input layers. Weights are assigned to individual input which is then integrated by neurons; hence the output is determined according to activation function [72].

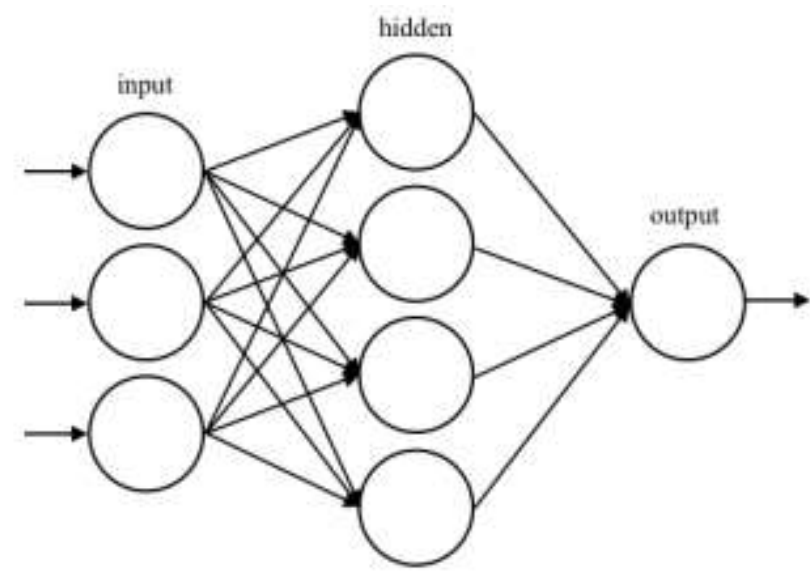

Fig. 12. Architecture of ANN

Primary procedure of developing ANN is the training mechanism that is either supervised or unsupervised [71]. Hence, anti-islanding scheme is developed by training the ANN with numerous variations of islanding situations [73]. Therefore, the SP extraction feature methods are applied to extract the data concentrating on required variable to train the ANN in differentiating islanding activity and other interference [46]. Limitation of ANN, though there is no NDZ area, includes indefinite islanding detection period with various sets of inputs even with inputs that are rather alike [70]. Besides, substantial processing period is required for feature selection procedure in addition to multiple DG structures that are required to be addressed [10].

\section{B Probabilistic Neural Network (PNN)}

There are a lot of other NN-based methods that share the same primary idea with ANN. One of the eminent schemes is Probabilistic Neural Network (PNN) that utilizes Bayesian classifier strategy. Principally, the Bayer formulation of PNN is as shown in (12).

$$
P(x \mid y)=\frac{P(y \mid x) \times P(x)}{P(y)} \#(12)
$$

where $P(x \mid y)$ is the probability of event $x$ while event $y$ provided, $P(y \mid x)$ is the probability of event $\mathrm{y}$ while event $\mathrm{x}$ provided, $P(x)$ is the probability of event $x, P(y)$ is the overall probability of all events $y$ [74]. PNN consists of several layers as depicted in Fig. 13 which are input, pattern, summation and output [75]. PNN harbor extremely rapid training speed compared to ANN in which eliminate the defect of lengthy computational period [76]. However, PNN require high memory capacity as well as high processing speed gadgetry.

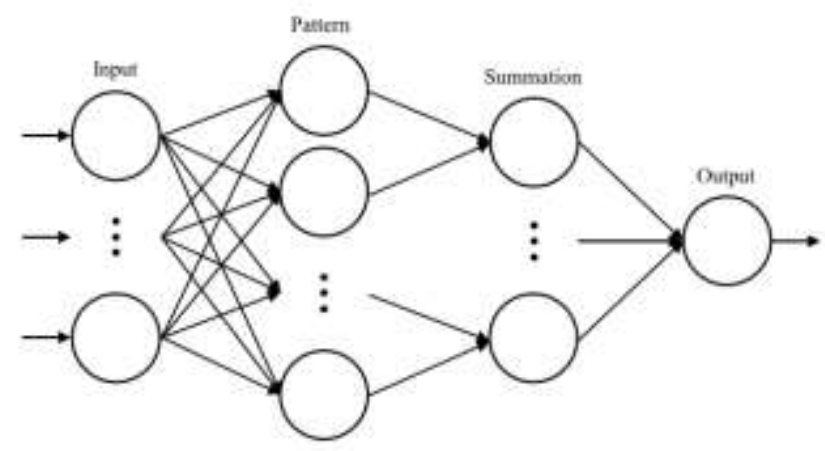

Fig. 13. Architecture of PNN

\section{Decision Tree (DT)}

The principle mechanism of DT method is dissecting the input for alleviation in a structure of a binary tree which is as shown in Fig. 14 [16]. In the beginning, the input data or the classification issues are regarded as the initial nodes (root node). Each of these nodes are split to two internal nodes (child nodes) based on a predictor variable. These nodes then kept being split repeatedly until terminal nodes (leaf node) which is a node that is unable to be further split is attained [77]. Eventually, predictions are performed based on these terminal nodes [46].

The main asset of DT is the rapid training procedure compared to other popular classifiers [78]. High correlation of different potential input variable can cause the selection activity that enhance model statistic, though the interest of output is unaffected [79]. Apart from the merits, the demerit is DT has high sensitivity to the external influence in which affects the prediction activity [80].

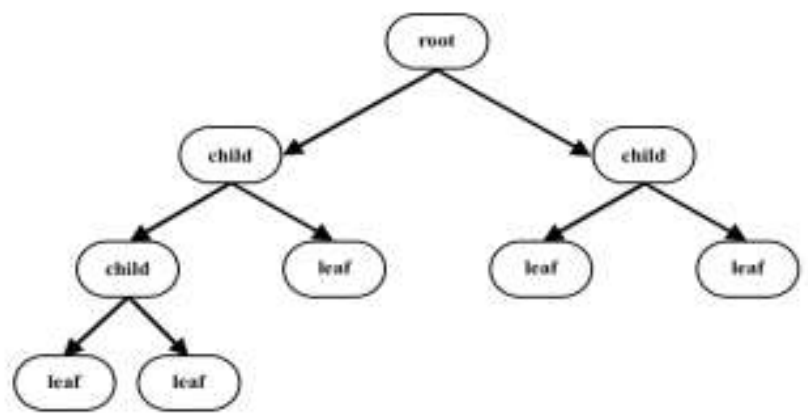

Fig. 14. Elementary DT architecture 


\section{A RESEARCH OF ISLANDING DETECTION METHOD FOR DISTRIBUTED GENERATION: MECHANISM, MERITS AND DEMERITS}

\section{CONCLUSION}

The paper contributes an overview of anti-islanding schemes for the integration of renewable energy sources with electrical distribution grid. The overview presented is concentrated on the method mechanism, merits and demerits. The IDMs can be broadly classified as classical and modern methods in which can be further classified to several methods based on the functional mechanism. Passive and active methods are the classification of local scheme which is one of the classical methods. Local means the islanding detection relay is applied at the PCC or the local DG terminal, while additional perturbation is injected for the active methods. Passive method has rapid detection speed, cheap as well as uncomplicated to be applied. However, the NDZ area is broad. The huge NDZ is decreased by applying active method, but unfortunately the perturbation injection is likely to affect hence degrading the DG output quality. Communication-based IDM or remote method is another variation of classical method which proposes to use communication means to detect islanding. The method totally eliminates NDZ, however a longer detection period and excessive expenditure is required. Hence, the issues arise causing researchers to hunt for other alternative methods, therefore inventing the modern method in which includes SP-based scheme and intelligent strategy. Modern method has no NDZ but the application intricacy is high. Therefore, further analysis with a concrete theoretical architecture as well as adequate practical demonstration is required in order to apply the modern scheme. Finally, it can be concluded that there is no ideal method invented till now or at least there is still no ideal practical demonstration. However, integration of these methods as well as proper implementation based on the grid structure might offer an ultimate anti-islanding scheme.

\section{REFERENCES}

1. N. Panigrahy, Ilamparithi T., M. V. Kashinath, and R. Prakash, "Comparison and review of islanding detection techniques for power distribution studies," International Journal of Advanced Research in Electrical, Electronics and Instrumentation Engineering, vol. 5, no. 7, July, pp. 6485-6492, 2016.

2. C. W. Yeau and Y. H. Tzer, "An integrated passive islanding detection method for distributed generators," WSEAS Transactions on Systems, vol. 8, no. 11, pp. 1207-1216, 2009

3. S. Raza, H. Mokhlis, H. Arof, J. A. Laghari, and L. Wang, "Application of signal processing techniques for islanding detection of distributed generation in distribution network: A review," Energy Conversion and Management, vol. 96, pp. 613-624, 2015.

4. M. Khodaparastan, H. Vahedi, F. Khazaeli, and H. Oraee, "A novel hybrid islanding detection method for inverter-based DGs using SFS and ROCOF," IEEE Transactions on Power Delivery, vol. 32, no. 5, pp. 2162 2170, 2017.

5. Virginia Tech. (2007). Consortium in energy restructuring: Introduction to DG and intentional islanding. [Online]. Available: https://www.dg.history.vt.edu/ch3/islanding.html.

6. S. K. G. Manikonda and D. N. Gaonkar, "Comprehensive review of IDMs in DG systems," IET Smart Grid, vol. 2, no. 1, pp. 11-24, 2019.
7. C. R. Reddy and K. H. Reddy, "An efficient passive islanding detection method for integrated DG system with zero NDZ," International Journal of Renewable Energy Research, vol. 8, no. 4, pp. 1994-2002, 2018.

8. K. Aziah, S. Hussain, B. Erdal, and K. Tamer, "A review of islanding detection techniques for renewable distributed generation systems," Renewable and Sustainable Energy Reviews, vol. 28, pp. 483-493, 2013.

9. P. Gupta, R. S. Bhatia, and D. K. Jain, "Average absolute frequency deviation value based active islanding detection technique," IEEE Transactions on Smart Grid, vol. 6, no. 1, pp. 26-35, 2015.

10. K. Min Sung, H. Raza, C. Gyu Jung, K. Chul Hwan, W Chung Yuen, and C. Jong Seo, "Comprehensive review of islanding detection methods for distributed generation systems," Energies, vol. 12, no. 5, pp. 837-857, 2019.

11. H. Samet, F. Hashemi, and T. Ghanbari, "Minimum non detection zone for islanding detection using an optimal Artificial Neural Network algorithm based on PSO," Renewable and Sustainable Energy Reviews, vol. 52, pp. 1-18, 2015.

12. C. R. Reddy and K. H. Reddy, "Islanding detection techniques for grid integrated distributed generation-A review," International Journal of Renewable Energy Research, vol. 9, no. 2, pp. 960-977, 2019.

13. Soumya A. V. and J. Belwin Edward, "Review of islanding detection techniques for distributed energy sources," IARJSET, vol. 3, no. 3, pp. 135-138, 2016.

14. M. Yingram and S. Premrudeepreechacharn, "Investigation over/under-voltage protection of passive islanding detection method of distributed generations in electrical distribution systems," IEEE International Conference on Renewable Energy Research and Applications, pp. 1-5, 2012.

15. C. Trujillo, D. Velasco, E. Figueres, and G. Garcera, "Local and remote techniques for islanding detection in distributed generators," in Distributed Generation, D. N. Gaonkar, Ed. London: InTechOpen, 2010, pp. 119-140.

16. S. Dutta, P. K. Sadhu, M. J. B. Reddy, and D. K. Mohanta, "Shifting of research trends in islanding detection method-a comprehensive survey," Protection and Control of Modern Power Systems, vol. 3, no. 1, pp. $1-20,2018$

17. C. R. Reddy and K. H. Reddy, "Islanding detection method for inverter based distributed generation based on combined changes of ROCOAP and ROCORP," International Journal of Pure and Applied Mathematics, vo. 117 , no. 19 , pp. 433-440, 2017.

18. S. Nikolovski, H. Reza Baghaee, and D. Mlakic, "Islanding detection of synchronous generator-based DGs using reactive power rate of change," IEEE Systems Journal, pp. 1-11, 2019.

19. C. Asad Ali, J.A. Laghari, S. Khokhar, and A. Suhail Ahmed, "A new islanding detection technique based on rate of change of reactive power and radial basis function neural network for distributed generation," Journal of Intelligent and Fuzzy Systems, vol. 37, no. 2, pp. 2169, 2019.

20. D. Laverty, R. Best, and D. J. Morrow, "Loss-of-mains protection system by application of phasor measurement unit technology with experimentally assessed threshold settings," IET Generation, Transmission \& Distribution, vol. 9, no. 2, pp. 146-153, 2015.

21. X. Jinlei and M. Longhua, "A new passive islanding detection solution based on accumulate phase angle drift," Applied Sciences, vol. 8, no. 8, pp. 1340-1356, 2018 . 
22. P. Gupta, R. S. Bhatia, and D. K. Jain, "Active ROCOF relay for islanding detection," IEEE Transactions on Power Delivery, vol. 32, no. 1, pp. 420-429, 2017.

23. A. Shahrokh, M. Sarailoo, A. Arash, and A. Asgar Ghadimi, "A novel hybrid approach using SMS and ROCOF for islanding detection of inverter-based DGs," IEEE Power and Energy Conference, pp. 1-7, 2017.

24. S. Khichar and M. Lalwani, "An analytical survey of the systems," Techol Econ Smart Grids Sustain Energy, vol. 3, no. 10, pp. 1-10, 2018.

25. J. S. Il and K. K. Ho, "An islanding detection method for distributed generations using voltage unbalance and total harmonic distortion of current," IEEE Transactions on Power Delivery, vol. 19, no. 2, pp. 745-752, 2004.

26. L. Canbing, C. Chi, C. Yijia, K. Yonghong, Z. Long, and F. Baling, "A review of islanding detection methods for microgrid," Renewable and Sustainable Energy Reviews, vol. 35, pp. 211-220, 2014

27. L. Ning, A. Abdualah, D. Chris, C. Liuchen, and S. Jianhui, "Passive islanding detection approach based on tracking the frequency dependent impedance change," IEEE Transactions on Power Delivery, vol. 30, no. 6, pp. 2570-2580, 2015.

28. P. Yazdkhasti and C. Diduch, "An islanding detection method based on measuring impedance at the point of common coupling," IEEE Canadian Conference on Electrical and Computer Engineering, 2015, pp. 57-62.

29. K. A. K. N. Edhura, S. Jeyraj, and A. R. Nasrudin, "A review of the islanding detection methods in gridconnected PV inverters," Renewable and Sustainable Energy Reviews, vol. 21, pp. 756-766, 2013.

30. B. Mohammadpour, M. Pahlevaninezhad, S. Makhdoomi Kaviri, and P. Jain, "A new slip mode frequency shift islanding detection method for single phase grid connected inverters," IEEE International Symposium on Power Electronics for Distributed Generation Systems, pp. 1-7, 2016.

31. A. Shahrokh, A. Arash, and A. Asghar Ghadimi, "Performance analysis of the slip mode frequency shift islanding detection method under different inverter interface control strategies," IEEE Power and Energy Conference, pp. 1-7, 2016.

32. J. N. Patel, "Islanding detection techniques for distributed energy resources-Review," International Journal of Innovative Research in Science, Engineering and Technology, vol. 5, no. 4, pp. 5709-5716, 2016.

33. H. Wen, Z. Tao, Y. Fei, W. Zengping, X. Shiguang, W. Xiaoli, and G. Tianxiang, "Analysis of the NDZ formulation theory of active frequency shift islanding detection method for grid-connected PV system," IEEE PES Asia-Pacific Power and Energy Engineering Conference, pp. 1-5, 2014.

34. A. Hatata and B. E. Sedhom, "A review of anti-islanding protection methods for renewable distributed generation systems," Journal of Electrical Engineering, vol. 16, no. 1, pp. 1-12, 2016.

35. L. Ying, H. Meiyi, F. Han, and L. Xincai, "Composite islanding detection method based on the active frequency drift and voltage amplitude variation," IEEE PES AsiaPacific Power and Energy Engineering Conference, pp. $1-6,2015$

36. A. G. Abokhalil, A. A. Bilal, and A. Q. A. Rahman, "Comparative study of passive and active islanding detection methods for PV grid-connected systems," Sustainability, vol. 10, no. 6, pp. 1798-1812, 2018.

37. W. Bower and M. Ropp, "Evaluation of islanding detection methods for photovoltaic utility-interactive power systems," International Energy Agency, USA, Report IEA PVPS T5-09, 2002. islanding detection techniques of distributed generation

38. M. E. Ropp, M. Begovie, and A. Rohatgi, "Analysis and performance assessment of the active frequency drift method of islanding prevention," IEEE Transactions on Energy Conversions, vo. 14, no. 3, pp. 810-816, 1999.

39. M. V. G. Reis, M. G. Villalva, T. A. S. Barros, A. B Moreira, and E. Ruppert, "Active frequency drift with positive feedback anti-islanding method for a single phase two-stage grid-tied photovoltaic system," IEEE 13th Brazilian Power Electronics Conference and 1st Southern Power Electronics Conference, pp. 1-6, 2016.

40. M. V. G. Reis, T. A. S. Barros, and A. B. Moreira, "Analysis of the Sandia Frequency Shift (SFS) islanding detection method with a single-phase photovoltaic distributed generation system," IEEE PES Innovative Smart Grid Technologies Latin America, 2015, pp. 125129.

41. Y. Lu, Z. Dahai, and H. Jinghan, "Active islanding detection method for multi-inverter in power distribution system," IEEE Conference on Energy Internet and Energy System Integration, pp. 1-5, 2018.

42. H. Vahedi and M. Karrari, "Adaptive fuzzy Sandia frequency-shift method for islanding protection of inverter-based distributed generation," IEEE Transactions on Power Delivery, vol. 28, no. 1, pp. 8492, 2013.

43. J. A. Laghari, H. Mokhlis, A. H. A. Bakar, and M Karimi, "A new islanding detection technique for multiple mini hydro based on rate of change of reactive power and load connecting strategy," Energy Conversion and Management, vol. 76, pp. 215-224, 2013.

44. P. Mahat, Z. Chen, and B. B. Jensen, "A hybrid islanding detection technique using average rate of voltage change and real power shift," IEEE Transactions on Power Delivery, vol. 24, no. 2, pp. 764-771, 2009.

45. C. W. Yeau, "A hybrid islanding detection method distributed synchronous generators," International Power Electronics Conference, 2010, pp. 1326-1330.

46. J. A. Laghari, H. Mokhlis, M. Karimi, A. H. A. Bakar, and M. Hasmaini, "Computational intelligence based techniques for islanding detection of distributed generation in distribution network: A review," Energy Conversion and management, vol. 88, pp. 139-152, 2014.

47. G. bayrak, "A remote islanding detection and control strategy for photovoltaic-based distributed generation systems," Energy Conversion and Management, vol. 96, pp. 228-241, 2015

48. M. E. Ropp, K. Aaker, J. Haigh, and N. Sabbah, "Using power line carrier communications to prevent islanding," IEEE Photovoltaic Specialist Conference, 2002, pp $1675-1678$

49. X. Wilson, Z. Guibin, L. Chun, W. Wencong, W. Guangzhu, and K. Jacek, "A power line signaling based technique for anti-islanding protection of distributed generators-Part I: Sheme and analysis," IEEE Transactions on Power Delivery, vol. 22, no. 3, pp. 17581766, 2007.

50. A. Pinomaa, A. Poluektov, J. Ahola, and A. Kosonen, "Analysis of channel characteristics and modeling of a transformer for PLC-based loss-of-mains concept," International Symposium on Power Line Communications and its Applications, pp. 230-235, 2016.

51. G. Bayrak and E. Kabalci, "Implementation of a new remote islanding detection method for wind-solar hybrid power plants," Renewable and Sustainable Energy Reviews, vol. 58, pp. 1-15, 2016.

52. C. I. Chen and C. Y. Chin, "Intelligent identification of 

MERITS AND DEMERITS

voltage variation events based on IEEE Std. 1159-2009 for SCADA of distributed energy system," IEEE Transactions on Industrial Electronics, vol. 62, no. 4, Apr., pp. 2604-2611, 2015.

53. A. Kitamura, M. Okamoto, F. Yamamoto, K. Nakaji, H. Matsuda, and K. Hotta, "Islanding phenomenon elimination study at Rokko test center: Characteristics comparison of the reactor method and capacitor method," IEEE World Conference on Photovoltaic Energy Conversion, 1994, pp. 759-762.

54. C. N. Papadimitriou, V. A. Kleftakis, and N. D. Hatziargyriou, "A novel islanding detection method for microgrids based on variable impedance insertion," Electric Power System research, vol. 121, pp. 58-66, 2015.

55. M. Kahrobaee, Analysis of local anti-islanding detection methods for photovoltaic generators in distribution systems. Master thesis, Lincoln: University of Nebraska, 2019.

56. S. Khokhar, M. Z. A. Asuhaimi, M. A. Safawi, and M. Pesaran, "A comprehensive overview on signal processing and artificial intelligence techniques applications in classification of power quality disturbances," Renewable and Sustainable Energy Reviews, vol. 51, Nov., pp. 1650-1663, 2015.

57. P. F. Ribeiro, P. M. da Silveira, C. A. Duque, and A. S. Cerqueira, Power Systems Signal Processing for Smart Grids. New Jersry: John Wiley and Sons, 2014.

58. D. Voglitsis, N. P. Papanikolaou, and A. C. Kyritsis, "Active cross-correlation anti-islanding scheme for PV module-integrated converters in the prospect of high penetration levels and weak grid conditions," IEEE Transactions on Power Electronics, vol. 34, no. 3, pp. 2258-2274, 2019.

59. A. Dabrowski and T. Marciniak, "Canonic Goertzel algorithm and drwabacks of various Goertzel algorithm formulations," Signal Processing: Algorithms, Architectures, Arrangements, and Applications, pp. 259262, 2017.

60. Z. Yanping, Y. Qiuxia, W. Junjuan, Z. Dezhong, and T. Yuexin, "A novel islanding detection method of distributed generator based on wavelet transform," International Conference on Electrical Machines and Systems, 2009, pp. 2686-2688.

61. W. G. Morsi, C. P. Diduch, and L. Chang, "A new islanding detection approach using wavelet packet transform for wind-based distributed generation," International Symposium on Power Electronics for Distributed Generation Systems '2, 2010, pp. 495-500.

62. S. R. Mohanty, N. Kishor, P. K. Ray, and J. P. S. Catalo, "Comparative study of advance signal processing techniques for islanding detection in a hybrid distributed generation system," IEE Transactions on Sustainable Energy, vol. 6, no. 1, pp. 122-131, 2015.

63. R. G. Stockwell, L. Manisha, and R. P. Lowe, "Localization of the complex spectrum: The S transform," IEEE Transactions on Signal Processing, vol. 44, no. 4, pp. 998-1001, 1996.

64. S. R. Mohanty, N. Kishor, P. K. Ray, and J. P. S. Catalao, "Islanding detection in a distributed generation based hybrid system using intelligent pattern recognition techniques," IEEE PES Innovative Smart Grid Technologies Europe, pp. 1-5, 2012.

65. N. E. Huang, S. Zheng, S. R. Long, M. C. Wu, H. H. Shis, Z. Quanan, Y. N. Chyuan, T. C. Chao, and H. H. Liu, "The empirical mode decomposition and the Hilbert spectrum for nonlinear and non-stationary time series analysis," The Royal Society, vol. 454, pp. 903-995, 1998.

66. A. M. Jasa, S. Danny, and S. David, "Analysis of nonstationary power-quality waveforms using iterative
Hilbert Huang transform and SAX algorithm," IEEE Transactions on Power Delivery, vol. 28, no. 4, pp. 2134 2144, 2013.

67. P. Maragos and R. Schafer, "Morphological filters-Part I: Their set theoretic analysis and relations to linear shiftinvariant filters," IEEE Transactions on Acoustics, Speech, and Signal Processing, vol. 35, no. 8, pp. 1153$1169,1987$.

68. M. Mishra and P. K. Rout, "Loss of main detection in distribution generation system based on hybrid signal processing and machine learning technique," International Transactions on Electrical Energy Systems, vol. 29, no. 1, pp. 1-26, 2018.

69. F. M. Aneesa and K. S. Swarup, "Mathematical morphology-based islanding detection for distributed generation," IET Generation, Transmission and Distribution, vol. 10, no. 2, pp. 518-525, 2016.

70. M. H. Amini, K. G. Boroojeni, S. S. Iyengar, P. M. Parados, F. Blaabjerg, and A. M. Madni, Sustainable Interdependent Network II: From Smart Power Grids to Intelligent Transportation Networks. Cham: Springer, 2019.

71. H. Kukreja, N. Bharath, C. S. Siddesh, and S. Kuldeep, "An introduction to artificial neural network," International Journal of Advance Research and Innovative Ideas in Education, vol. 1, no. 5, pp. 27-30, 2016.

72. J. A. Laghari, H. Mokhlis, M. Karimi, A. H. A. Bakar, and A. Shahriari, "Artificial neural network based islanding detection technique for mini hydro type distributed generation," IET International Conference on Clean Energy and Technology, pp. 1-6, 2014.

73. V. L. Merlin, R. C. Santos, A. P. Grilo, J. C. M. Vieira, D. V. Coury, and M. Oleskovicz, "A new artificial neural network based method for islanding detection of distributed generators," International Journal of Electric Power \& Energy Systems, vol. 75, pp. 139-151, 2016.

74. K. Aziah, S. Hussain, M. Azah, and B. Erdal, "Islanding detection in a distributed generation integrated power system using phase space technique and probabilistic neural network," Neurocomputing, vol. 148, pp. 587-599, 2015.

75. A. Masoud, H. Hashim, O. M. Luthfi, and R. M. Amran, "Islanding detection method using ridgelet probabilistic neural network in distributed generation," Neurocomputing, vol. 329, pp. 188-209, 2019.

76. K. Aziah and H. Shareef, "An effective islanding detection and classification method using neuro-phase space technique," International Scholarly and Scientific Research and Innovation, vol. 7, no. 6, pp. 711-719, 2013.

77. S. Vyas, R. Kumar, and R. Kavasseri, "data analytics and computational methods for anti-islanding of renewable energy based distributed generators in power grids," Renewable and Sustainable Energy Reviews, vol. 69, pp. 493-502, 2017.

78. M. Heidari, G. Seifossadat, and M. Razaz, "Application of decision tree and discrete wavelet transform for an optimized intelligent-based islanding detection method in distributed systems with distributed generations," Renewable and Sustainable Energy Reviews, vol. 27, pp 525-532, 2013.

79. S. Y. Yan and L. Ying, "Decision tree methods Applications for classification and prediction," Shangha Archives of Psychiatry, vol. 27, no. 2, pp. 130-135, 2015.

80. T. I. Lytvynenko, "Problem of data analysis and 
forecasting using decision tree method," International Conference of Programming, 2016, pp. 220-226.

81. M. H. Hairi, Q. Shaofan, L. Haiyu, and D. Randles, "Impact of PV generation on low voltage networks," International Universities Power Engineering Conference, pp. 1-5, 2012.

a. H. Hairi and L. Haiyu, "Sensitivity and stability analysis of loss of main protection in active distribution networks," IEEE PES General Meeting, pp. 1-5, 2014.

\section{AUTHORS PROFILE}

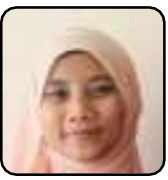

Nuraishahtul Amirah Fadzil was awarded a Bachelor's Degree in Electrical and Electronics Engineering majoring in Power by the National Defence University of Malaysia (UPNM) in 2014. Upon graduation, she worked as a System Designer in Aircomaster Sdn. Bhd before serve as a young lecturer in UPNM until 2018. Currently, she is pursuing her master in Technical University of Malaysia Malacca (UTEM) and her research interest is antiislanding methodology.

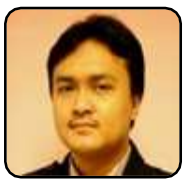

Mohd Hendra Hairi (Phd, MIEEE, MIET) received his Bachelor's degree in Electrical Engineering from University Sains Malasyia in 2001 and Master of Science degree in Electrical Power Engineering from Universiti Teknologi Malaysia in 2003. He received his Ph.D degree from University of Manchester in 2015. He has served as an academic staff at Universiti Teknikal Malaysia Melaka (UTeM) since 2003 and he is currently a senior lecturer in the Faculty of Electrical Engineering (FKE), UTeM. He was formerly the Head of Energy and Power System group (EPS), FKE. He is an expert in power system protection and his research interests included power system, renewable energy and distributed generation.

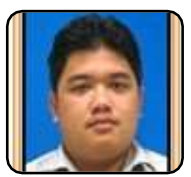

Farhan Hanaffi received his Bachelor's degree in Electrical Engineering and Master of Electrical Engineering (Power) from Universiti Teknologi Malaysia in 2006 and 2008. He received his Ph.D from University of Strathclyde, Glasgow, in 2016. He has served as an academic staff at Universiti Teknikal Malaysia Melaka (UTEM) since 2008 and he is currently a senior lecturer at the Faculty of Electrical Engineering, UTeM. His research interests include power system, high voltage, lightning protection and electrical grounding system.

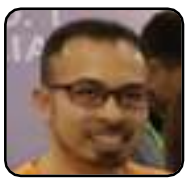

Muhammad Nizam Kamarudin was born in Selangor, Malaysia. He received the B. Eng (Hons) Electrical from the Universiti Teknologi MARA, Malaysia in 2002, and M.Sc in Automation and Control from the University of Newcastle Upon Tyne, United Kingdom in 2007. He received the Doctor of Philosophy in Electrical Engineering from the Universiti Teknologi Malaysia in 2015. He is currently with the Universiti Teknikal Malaysia Melaka (UTeM). He is a member of the Board of Engineers, Malaysia and Institute of Engineers, Malaysia.

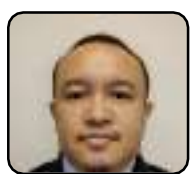

Ahmad Sadiqhin Mohd Isira received his Master of Engineering Degree in Electrical Engineering from Universiti Teknologi Malaysia (UTM), Malaysia, in 2008. He later obtained his $\mathrm{PhD}$ degree in Control Engineering from School of Electrical and Electronics, University of Manchester, UK in 2016. Currently he is a lecturer of Faculty of Electronics and Computer Engineering, Universiti Teknikal Malaysia Melaka. His research interests include nonlinear control, energy harvesting and automation control system. 